\title{
Historia y memoria en Argentina: análisis de la dictadura militar (1976-1983) a través del cine como estrategia de intervención alternativa en el escenario escolar
}

History and Memory in Argentina: an Analysis of the Military Dictatorship (1976-1983) Through Cinema as an Alternative Intervention Strategy in the School Setting

História e memória na Argentina: análise da ditadura militar (1976-1983) através do cinema como estratégia de intervenção alternativa no cenário escolar

\section{Nicolás Patierno* iD orcid.org/0000-0002-3411-7309}

\section{Sabrina Mabel Martino Ermantraut ${ }^{* *}$ (D) orcid.org/0000-0001-6691-337X}

\section{Artículo de investigación}

Revista Colombiana de Educación, N. 기. Segundo semestre de 2016, Bogotá, Colombia.

Para citar: Patierno, N, y Martino, S. M. (2016). Historia y memoria en Argentina: análisis de la dictadura militar (1976-1983) a través del cine como estrategia de intervención alternativa en el escenario escolar. Revista Colombiana de Educación, (71), 279-297. 


\section{Resumen}

El propósito de este artículo es llevar a cabo un breve recorrido por los hechos acontecidos en el campo educativo durante la última dictadura militar argentina, rescatando diversos materiales filmicos vinculados con el pasado reciente. En este sentido, el texto también pretende problematizar la cuestión de la memoria en el escenario educativo argentino, analizando temas como la relevancia de la historia contemporánea en la comprensión del entramado socio-político, la adecuación de estos contenidos a los diversos niveles (con particular atención en el nivel secundario) y las potencialidades que ofrece la historia contemporánea como ejercicio de reflexión. El material recolectado incluye bibliografía y filmografía especializada; en su mayoría, contenidos publicados con posterioridad al periodo de censura (comprendido en Argentina entre los años 1976-1983). La propuesta de intervención incluye el cine como una estrategia no convencional, no solo por tratarse de un recurso alternativo en el escenario escolar cotidiano, sino por sus potencialidades vinculadas al uso de la imagen y el diálogo.

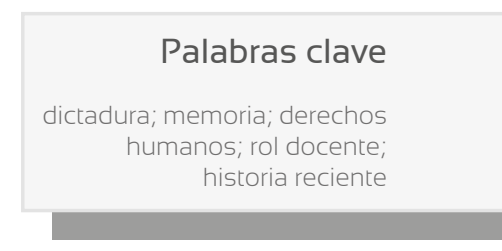

\section{Keywords}

dictatorship; memory; human rights; teaching role; recent history

\begin{abstract}
The purpose of this article is to conduct a brief tour of the events that took place in the educational field during Argentina's military dictatorship. The text is also aimed at problematizing the question of memory in the Argentine educational system, analyzing topics such as the relevance of contemporary history in understanding the socio-political framework, the adequacy of these contents to various levels (with particular attention the secondary level) and the potential offered by contemporary history as an exercise of reflection. Furthermore, the article looks at these themes from an educators' perspective, in order to present it to future generations. Films will be the chosen media to analyse these matters, through the search of archives from different sources. This proposal is based on the potential offered by the cinema, like the use of images and dialogue.
\end{abstract}

\section{Resumo}

O proposito deste artigo é levar á cabo um breve recorrido pelos acontecimentos no campo educativo durante á última ditadura militar argentina, salvando diversos materiais visuais em relação com o passado recente. Neste sentido, o texto também busca problematizar a questão da memória no ambiente educativo argentino analisando temas como a relevância da história contemporânea na compreensão do âmbito sócio-político, a educação destes contidos aos diferentes níveis (com particular atenção ao nível secundário) e as potencialidades oferecidas pela história contemporânea como exercício de reflexão. $\bigcirc$ material recolhido inclui bibliografía e filmografía especializada; a maior parte, contidos publicados logo do período de censura (entendido na Argentina entre os anos 1976-1983) A proposta de intervenção inclui o cinema como uma estratégia não convencionai, não só por ser um recurso alternativo no âmbito escolar cotidiano, mas por as potencialidades ligadas ao uso da imagem e o diálogo.

\section{Palavras chave}

ditadura; memória; direitos humanos; o papel docente; história recente

$\mathrm{N}^{\circ}{ }^{\circ} 71$ 


\section{Breve recorrido histórico}

$\mathrm{H}$ acia mediados de la década de 1970, tras la muerte de Juan Domingo Perón y la sucesión del mando a su segunda esposa, Isabel Perón, se vislumbraba una incipiente descomposición del Gobierno. Sumado a ello, factores como el desajuste económico y la violencia política se transformaron progresivamente en los sellos característicos de la época. Así, el general Jorge R. Videla (miembro del Ejército), el almirante Emilio E. Massera (miembro de la Marina) y el brigadier Orlando R. Agosti (miembro de la Aeronáutica), los tres comandantes de la armada, integraron la llamada "Junta Militar", que el 24 de marzo de 1976 derrocó al gobierno de Isabel Perón. Esta nueva intervención militar fue totalmente diferente a las anteriores, puesto que se estableció un modo de gobierno basado en el terror, la ideología y la propaganda; este golpe de Estado se autodenominó "Proceso de Reorganización Nacional".

Las estrategias Ilevadas a cabo por la Junta Militar para el ejercicio del poder se asemejaban a las que pusieron en marcha los totalitarismos del siglo xx. Desde nuestro punto de vista, el concepto de dictadura, y más específicamente el modo en que esta se ejecutó en Argentina, adopta componentes del totalitarismo, del autoritarismo y replica técnicas de tortura llevadas a cabo por militares europeos en diversos conflictos armados de mediados del siglo xx.

La supuesta "necesidad" de restaurar el orden se convirtió, en el caso argentino, en el discurso utilizado para legitimar el accionar de la dictadura militar y la sistemática violación a los derechos humanos. Dicho régimen se amparó en el establecimiento de numerosos centros clandestinos de detención, un componente clave en el sistema de gobierno totalitario. Estos elementos de coacción estuvieron acompañados por la aplicación de torturas sistemáticas, Ilevadas a cabo no solo por personal militar, sino también por civiles, como es el caso de los médicos que acompañaban y verificaban la aplicación de tormentos.

En lo que respecta a la violación de los derechos humanos, un documento elaborado por la Comisión Nacional sobre la Desaparición de Personas (Conadep) en el año 1985 da cuenta de lo que sucedía en el país puertas adentro de los centros clandestinos de detención. La comisión, presidida por Ernesto Sábato y bajo las instrucciones del entonces presidente Raúl Alfonsín, se encargó de compilar las denuncias sobre la desaparición y el secuestro de personas durante el periodo comprendido entre 1976 y 1983. El documento denominado Nunca Más es una compilación de aproximadamente diez mil denuncias y la confirmación de nueve mil desapariciones al año de su primera edición. Esta cifra ascendió a unos treinta mil con el paso de los años y con la llegada de nuevas denuncias; este proceso de confirmación de desapariciones se pudo completar de

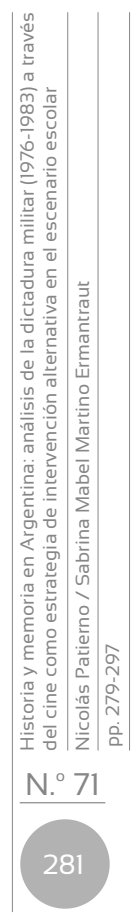


manera progresiva y a lo largo de varios años, puesto que el terror asociado a la dictadura se extendió en el imaginario social, Ilegando incluso hasta la actualidad. En lo que respecta a la violación de los derechos humanos, el informe señala:

De la enorme documentación recogida por nosotros se infiere que los derechos humanos fueron violados en forma orgánica y estatal por la represión de las Fuerzas Armadas. Y no violados de manera esporádica sino sistemática, de manera siempre la misma, con similares secuestros e idénticos tormentos en toda la extensión del territorio (Conadep, 1985, p. 8).

El modo en que los militares efectuaban sus operativos por lo general consistía en una serie de pasos asociados al aislamiento de los sospechosos. Una vez conformada la "patota", o "grupo de tareas", se solicitaba a la policía e intendencia local la liberación del área sobre la que se pretendía actuar. Una vez puesto en marcha el operativo e identificado el domicilio o lugar de trabajo del sospechoso, este era obligado a ingresar a un vehículo civil (sin distinciones militares ni policiales) ${ }^{1}$. Acto seguido se lo aislaba en un centro de detención provisorio, que por lo general era la comisaría desde la que se inició el operativo, y posteriormente el sujeto era reubicado un centro clandestino de detención, donde era sometido a interrogatorios, torturas, violaciones y en el caso de las mujeres embarazadas, el secuestro de sus hijos recién nacidos. El destino de los sujetos puestos en cautiverio por lo general era la muerte y desaparición de sus restos, que eran ubicados en fosas comunes o arrojados al río en lo que se conoció como los "vuelos de la muerte". Sobre la desaparición de personas, el documento relevado subraya:

En nombre de la seguridad nacional, miles y miles de seres humanos, generalmente jóvenes y hasta adolescentes, pasaron a integrar una categoría tétrica y fantasmal: la de los Desaparecidos. Palabra - ¡triste privilegio argentino! - que hoy se escribe en castellano en toda la prensa del mundo (Conadep, 1985, p. 9).

En el film denominado La batalla de Argel (1966), es posible observar la implementación de diversos tormentos con el objetivo de obtener información relevante para los torturadores (en este caso particular, militares franceses sobre revolucionarios argelinos). Entre estos medios se encuentran las golpizas, el ahorcamiento, la aplicación de electricidad

1 En el caso de Argentina, esta impotencia y sumisión frente al orden político impuesto se tradujo en lo que Slavoj Zizek (2008) denomina una denegación fetichista: "Lo sé, pero rechazo asumir por completo las consecuencias de este conocimiento, de modo que puedo continuar actuando como si no lo supiese" (Zizek, 2008, p. 70). Esta conducta se extendió fundamentalmente sobre las clases medias y altas, ocultándose bajo la premisa popularmente conocida como "si fue secuestrado algo habrá hecho". 
y el ahogamiento. La aplicación de estas torturas-interrogatorios, evidenciadas en la guerra de Argelia, fue fielmente replicada en los centros clandestinos de detención argentinos durante la última dictadura militar².

Uno de los objetivos centrales de la dictadura se centró en la "reorganización" del supuesto caos político que caracterizaba a Argentina hacia principios de la década de 1970. Para lograrlo, utilizaron diversos medios de comunicación, incluso llegaron a disolver los fines para los que originalmente fueron implementados. Bajo el discurso que pretendía restablecer la autoridad supuestamente perdida a causa de las revueltas políticas entre militantes de izquierda, guerrilleros y tradicionalistas, se creó el vacío político ideal para que los líderes militares (con apoyo internacional de los Estados Unidos) asumieran el liderazgo del país y ocuparan por la fuerza todos los ministerios.

Al pretender confundir intencionadamente la violencia con el valor de la autoridad en la organización política de los Estados modernos, nos encontramos ante una confusión cuyas consecuencias -rastreables en la política argentina de los setenta- abrieron las puertas a una peligrosa legitimación de la violencia institucional. Esta es una reinterpretación políticamente deliberada respecto del significado tradicional de la autoridad (originalmente interpretada bajo la triada romana de religión, autoridad y tradición). Un fragmento de la obra de Arendt titulada Entre el pasado y el futuro pretende aclarar la confusión entre ambos términos y pone en evidencia sus usos indiscriminados:

Si la violencia cumple la misma función que la autoridad -es decir, hacer que la gente obedezca-, la violencia es autoridad. Una vez más, nos encontramos con los que aconsejan una vuelta a la autoridad porque piensan que solo si se vuelve a introducir la relación orden-obediencia se pueden solucionar los problemas de una sociedad de masas. [...] Todos los que confunden el totalitarismo con una estructura autoritaria, implícitamente igualan violencia y autoridad (Arendt, 1996, p. 113).

En el caso argentino, la confusión entre autoridad, violencia y dictadura dio como resultado, además de la implementación de instrumentos explícitamente totalitarios, la utilización de técnicas vinculadas al autoritarismo. En pocas palabras, bajo la legitimación de una necesaria "reorganización institucional", se reescribieron leyes, disposiciones y se decretó la vigencia del Estatuto del Proceso de Reorganización Nacional. Este documento se redactó con el fin de reemplazar la Constitución Nacional (vigente, a pesar de numerosas modificaciones, desde el año 1853). Un fragmento de uno de los textos que compone el estatuto, más

2 Véase al respecto el documental Escuadrones de la muerte. La escuela francesa (2003). Lainformación completa sobre el material fílmico mencionado se encuentra disponible en el apartado correspondiente a la filmografía.

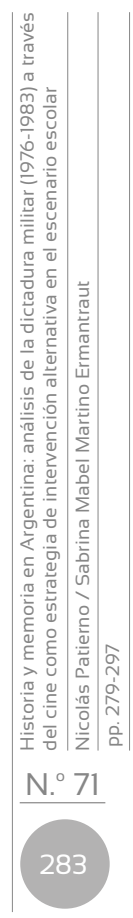


exactamente el Acta fijando el propósito y los objetivos básicos para el proceso de reorganización nacional, establece:

Frente a un tremendo vacío de poder, capaz de sumirnos en la disolución y en la anarquía; a la falta de capacidad de convocatoria que ha demostrado el Gobierno Nacional; a las reiteradas y sucesivas contradicciones evidenciadas en la adopción de medidas de toda índole; a la falta de una estrategia global que, conducida por el poder político, enfrentara la subversión; a la carencia de soluciones para problemas básicos de la Nación cuyo resultante ha sido el incremento permanente de todos los extremismos; [...] las Fuerzas Armadas en cumplimiento de una obligación irrenunciable han asumido la conducción del Estado (Estatuto del Proceso de Reorganización Nacional, 1980, p. 11).

Nótese la insistente mención respecto de términos asociados a la desvalorización institucional, al desprestigio de los gobiernos antecesores y al "vacío de poder". Para este diagnóstico, la Junta se reserva palabras como: disolución, anarquía, contradicciones, subversión y extremismos. Frente a estos términos, enmarcados en una fuerte connotación negativa y atemorizante -en un intento por evidenciar una realidad extremadamente caótica-, surge la "conducción" militar como la alternativa más conveniente, o más exactamente como la única alternativa posible. Esta proclama militar, asociada a la manipulación de discursos por parte de los regímenes totalitarios, se pronuncia como la única solución posible frente a un contexto apocalíptico, del que solo se puede salir con vida aceptando -pacífica y disciplinadamente-, las disposiciones arbitrariamente concebidas por la cúpula militar al mando. Este ejercicio explícito del autoritarismo se hace evidente en las escuelas, donde se distribuye de manera gratuita el documento citado y se subordina a un segundo plano la Constitución Nacional y su historia.

\section{La educación como instrumento de control social}

Siguiendo el análisis filosófico-político de Arendt (1996), podríamos afirmar que la educación es un espacio pre-político destinado a los más jóvenes; significa al joven lo que el trabajo al adulto, sin embargo, no puede prescindir de la intervención del último. La intromisión del adulto en la esfera educativa se halla ligada a dos principios fundamentales: la tradición y la autoridad. Estos principios son la base de la transmisión intergeneracional. La autoridad que descansa en el adulto y la tradición de determinado grupo social brindan al joven un espacio de contención, sin el cual este se vería arrojado a su propia suerte, esto es, desligado de las ventajas y los cuidados asociados a la herencia cultural.

En la compilación de ensayos titulada Entre el pasado y el futuro, publicada originalmente en la década de 1960, Arendt hace referencia 
a la educación y su relación con la esfera política del siguiente modo: "La palabra educación tiene un sonido perverso en política; se habla de la educación, pero la meta verdadera es la coacción sin el uso de la fuerza" (1996, p. 188). Para la autora en cuestión, el espacio de la política solo puede estar ocupado por personas que ya están educadas -el accionar en política supone un diálogo horizontal donde se comparten preocupaciones y se asegura el lugar a la diversidad de opiniones-, situación opuesta a la acontecida en un sistema dictatorial: la política se aísla del diálogo y la educación se traduce en un tipo de instrucción que solo admite obediencia. "El propósito de la educación totalitaria nunca ha sido inculcar convicciones, sino destruir la capacidad para formar alguna" (Arendt, 1998, p. 696). Si bien los modelos de gobiernos totalitarios y dictatoriales no son similares, la educación pensada por los militares argentinos se acerca a la ya citada. Más que un sistema pensado para la transmisión de saberes relevantes, la educación se redujo a un instrumento destinado al ejercicio despótico del poder.

Con una modalidad explícita de educación destinada a legitimar el accionar del Gobierno, la Junta no solo intentaba asegurarse del convencimiento ideológico de las nuevas generaciones, sino también de las familias, las autoridades y los docentes. Todo aquel que se pronunciase en contra de este objetivo o era considerado un obstáculo en la transmisión de los "valores nacionales" corría el riesgo de ser secuestrado y posteriormente torturado en los centros clandestinos de detención. Con respecto a las universidades, es importante destacar que estas no quedaron al margen del accionar militar. Bajo las directivas del jefe de la Marina, el almirante Emilio Eduardo Massera, la dictadura extendió su dominio a estos territorios. Estas instituciones no solo eran focos de interés para la inteligencia militar y el secuestro de personas, sino que también formaron parte de la "guerra psicológica": el cierre de algunas carreras y la censura de contenidos "subversivos" se transformaron en los principales modos de intervención dictatorial. Junto a los lugares de trabajo, los sindicatos y las asociaciones independientes, las universidades debieron acatar el modo de hacer militarista, esto es, subordinar la reflexión y el libre-pensamiento a la normativa vigente. En caso contrario, se corría el riesgo de padecer la detención y el posterior interrogatorio. En términos de Di Nella:

El plan del ejército revela una gran preocupación por la acción psicológica como herramienta de operación [...]. Las Universidades Nacionales, incluida la carrera de Psicología, estaban bajo el control de la Marina [...], quizás porque esta fuerza, a diferencia de la Aeronáutica y el Ejército, eran los más formados universitariamente, es decir, tenían más cuadros universitarios (2007, p. 135).

La "guerra psicológica" estaba dirigida al "público afectado" por las acciones anti-subversivas. Algo así como un remedio necesario para 
amortiguar los efectos colaterales causados por el uso de la violencia institucional. Para ello se utilizaron los medios de comunicación gráficos, el cine, la radio, la televisión, todos ellos bajo el estricto control y la consecuente censura por parte del entonces Ministerio de Cultura y Educación (ministro Juan José Catalán). Al respecto, el portal destinado a Educación y Memoria reconoce: "la cultura y la educación eran consideradas por los dictadores como un campo de batalla contra la subversión" ${ }^{\prime 3}$.

El accionar militar de la dictadura en espacios educativos llegó incluso a los niveles medios, tal es el caso de los hechos ocurridos la noche del 16 de septiembre de 1978 en la ciudad de La Plata. En esa ocasión, los militares secuestraron, torturaron y desaparecieron a jóvenes de entre 16 y 19 años de edad, quienes se encontraban por esos días reclamando la extensión de un boleto de micro de costo reducido para los estudiantes secundarios. Estos hechos inspiraron la creación de un film, basado en el libro homónimo: La noche de los lápices. Un breve relato de Pablo Díaz (estudiante de un colegio secundario y único sobreviviente de los secuestros), da cuenta de lo ocurrido:

Sabíamos que había un cana que anotaba nuestros nombres y nos fichaba. Estaban al pie del cañón todos los chicos [...]. Decidimos que la marcha se haría con o sin represión y todos estuvimos de acuerdo, hasta que uno de los chicos dijo que si había represión era mejor pedirle a una organización guerrillera que nos protegiera. Se armó un revuelo bárbaro y al pibe casi lo echan, pero se arregló que cada colegio pusiera su propia seguridad (Seoane y Núñez, 1986, p. 25).

El sistema educativo público, en todos sus niveles, significó mucho más que un ministerio para la dictadura militar Argentina. Allí se encontraba la base de la ideología, la red de establecimientos educativos más grande del país y el lugar donde confluían -y aún lo continúan haciendolas nuevas generaciones de todas las clases sociales. Escuelas, institutos y universidades conformaron espacios propicios para el ejercicio del control ideológico; tarea llevada a cabo fundamentalmente a través del estricto control de los contenidos, la didáctica, la disciplina y en algunos casos -mayormente documentados en las grandes ciudades-, el secuestro y la desaparición de personas. Este interés del gobierno militar por manipular todo lo referente al nivel educativo se hace explícito en el año 1977, a través de la publicación del documento titulado Subversión en el ámbito educativo. Este texto tenía como objetivo convertirse en una especie de manual destinado a la "prevención" de acciones subversivas en escuelas

3 La información completa sobre el portal del Ministerio de Educación destinado a la divulgación de la memoria reciente en contextos educativos se encuentra disponible en http://educacionymemoria.educ.ar/primaria/21/vida-cotidiana-durante-ladictadura/ censura/. 
secundarias y universidades. Entre sus contenidos se destacan un ferviente rechazo al marxismo y al comunismo, la reiterada acusación por la que las guerrillas pretendían "manipular ideológicamente" a los jóvenes y una serie de definiciones, todas ellas con un fuerte contenido pro-militar, evidenciadas en la exaltación del accionar del gobierno del entonces presidente Jorge Rafael Videla.

\section{El compromiso histórico del educador}

Con la vuelta de la democracia, a nivel educativo surgió un nuevo compromiso, el de comunicar lo sucedido durante las décadas de los setenta y ochenta, y para esto se necesitaría hacerle frente a la censura y el terror impuesto por los sucesivos gobiernos militares. Para ello fue fundamental el compromiso de los educadores, ya que

los docentes, como el resto de los argentinos, emergieron de esos años más o menos afectados por el terror. Pero, a diferencia de otros compatriotas, tenían el trabajo de transmitir relatos sobre ese pasado, desde instituciones oficiales concebidas para la formación de los niños y jóvenes (Lorenz, 2006, p. 295).

Arendt (1996) propone pensar la cuestión intergeneracional y la responsabilidad de los adultos en la transmisión cultural como una tarea fundamental para la vida en sociedad. Si bien esta función se hace explícita en la escena educativa, la responsabilidad de las generaciones mayores resulta trascendental si se pretende asumir el valor de la historia en la vida humana. Una vida sin el acompañamiento de una historia; una sociedad que no se preocupa por reflexionar respecto de sus orígenes, de las promesas cumplidas o incumplidas y de las perspectivas de futuro, corre el riesgo de padecer la subordinación total, esto es, el ascenso al poder de regímenes capaces de manipular la historia y la naturaleza de una sociedad. Tal como sucedió en la Alemania de Hitler, en la Unión Soviética de Stalin, en la Italia de Mussolini, o en la Argentina de Videla, los sistemas de gobierno dictatoriales asumieron el control total de las instituciones y de la función ideológica que las acompañaba. A los objetivos de este artículo, la institución educativa resulta de fundamental importancia, no solo por tratarse de un espacio donde confluyen las masas de jóvenes de diversos sectores, sino también por el protagonismo que asume en la construcción de identidades colectivas. Este espacio, a la vez de reproductor por su carácter de dispositivo moderno, se convierte en revelador a la hora de problematizar sobre el sentido de la política y la vida en sociedad.

Los adultos enseñantes deben asumir una doble responsabilidad: en primer lugar, asegurar la transmisión de aquellos saberes relevantes para

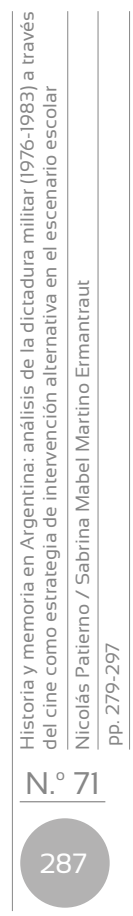


la vida en determinado grupo social, esto es, aquellos elementos que facilitan el ingreso de las nuevas generaciones al espacio social preexistente. En segundo lugar, la responsabilidad condicionada por la función de enseñante, la cual debe estar dirigida, en línea con el pensamiento de Arendt, hacia la búsqueda de verdades, no interpretadas como constantes universales, sino como revelaciones. En este sentido resulta de particular interés el film La historia oficial, no solo por tratar la temática de la desaparición de personas y el secuestro de bebés en tiempos de la dictadura, sino porque gran parte de la trama transcurre en un colegio secundario durante los años inmediatamente posteriores a la finalización del régimen. Este film merece una mención especial, no solo por haber ganado el Óscar a la mejor película de habla no inglesa -hecho que pone de manifiesto la preocupación internacional por los abusos en contra de los derechos humanos llevados a cabo en Argentina y en varios países latinoamericanos-, sino porque es una de las primeras veces que se menciona a las Abuelas de Plaza de Mayo en la pantalla grande, y de esta manera se legitima su histórica lucha por los desaparecidos ${ }^{4}$.

\section{El abordaje de la historia reciente en las escuelas secundarias}

En Argentina, tras la reapertura democrática, las decisiones en torno a políticas educativas estuvieron orientadas a promover el estudio del pasado reciente, en una clara voluntad de transmisión de valores democráticos, y de respeto y promoción de los derechos humanos. "Las temáticas asociadas a la noción de derechos humanos universales y a su historia, al estudio del pasado reciente argentino y a la formación ética y ciudadana ocupan lugares nada desdeñables en la currícula oficial" (Carnovale y Larramendy, 2010, p. 241). Cabe añadir que esta política de "no olvido" adquiere mayor relevancia en los periodos de gobierno kirchneristas (2003- 2015), puesto que el recuerdo de lo ocurrido en los años de dictadura fue una de las premisas más importantes que caracterizó a la época citada.

Al respecto es posible advertir la voluntad del gobierno de Néstor Kirchner con relación al abordaje de la memoria en contextos educativos, a través de la promulgación de leyes y la divulgación de material pedagógico. En este sentido, la Ley de Educación Nacional (2006), en su artículo 92 expresa:

4 Para complementar el abordaje didáctico sobre el tema de los desaparecidos y la recuperación de niños apropiados de manera ilegítima, recomendamos la serie de televisión (también publicada en DVD), denominada: Televisión por la identidad. Este proyecto fue realizado por las Abuelas de Plaza de Mayo en el año 2007 con motivo de concientizar a aquellos jóvenes que pudieran tener dudas sobre su identidad. 
Formarán parte de los contenidos curriculares [...] la causa de la recuperación de nuestras Islas Malvinas y el ejercicio y construcción de la memoria colectiva sobre los procesos históricos y políticos recientes que terminaron instaurando el terrorismo de Estado en nuestro país, con el objetivo de generar en los/as alumnos/as reflexiones y sentimientos democráticos y de defensa del Estado de Derecho y la plena vigencia de los Derechos Humanos (p. 19).

En sintonía con ello, el Ministerio de Educación Nacional lanzó el programa Educación y Memoria ${ }^{5}$ con el propósito de consolidar una política educativa que promueva la enseñanza de la historia reciente, creando materiales virtuales, audiovisuales y gráficos y poniéndolos a disposición de las escuelas secundarias, y ofreciendo capacitaciones a los docentes de todo el país. El Programa trabaja fundamentalmente en torno a tres ejes temáticos: terrorismo de Estado; memorias de la dictadura y la guerra de Malvinas.

También consideramos relevante destacar dos programas impulsados por el Espacio Memoria y Derechos Humanos destinado a escuelas secundarias $^{6}$. Se trata del programa Jóvenes y Memoria, impulsado desde 2011 y que tiene como objetivo el abordaje de la última dictadura cívico-militar y de problemáticas sociales presentes vinculadas a los derechos humanos. Este programa propone desarrollar una experiencia educativa que invite a los estudiantes a involucrarse activamente en sus realidades cotidianas con el objetivo de pensarse como sujetos de transformación. Para ello se plantea la elección de un tema o pregunta sobre sus realidades cotidianas, sus barrios, sus grupos de socialización, para luego iniciar una investigación con la intención de tender puentes entre el pasado y el presente. Se busca reflexionar sobre las rupturas y continuidades de la historia reciente así como también las conquistas, los alcances y los sentidos de las políticas de derechos humanos y la democracia. Los trabajos finales logrados por los estudiantes tienen una instancia de presentación a la cual asisten escuelas de distintos puntos del país. Por otro lado, el programa La Escuela Va a los Juicios propone, desde 2014, la concurrencia de estudiantes de 16 y 17 años a los juicios por delitos cometidos durante la última dictadura en Argentina, para luego trabajar con narrativas testimoniales en las clases. Estos juicios se consideran acontecimientos históricos que permiten condenar el terrorismo de Estado y reflexionar

5 Para más información, puede visitar el sitio oficial de Espacio Memoria y Derechos Humanos en http://educacionymemoria.educ.ar/secundaria/descargas/index.html

6 El Espacio Memoria y Derechos Humanos está situado en el predio que utilizaba la Escuela de Mecánica de la Armada (esma) como centro de detención clandestina durante la última dictadura cívico-militar en Argentina (1976-1983). Fue creado el 24 de marzo de 2004 en respuesta al reclamo histórico de los organismos de derechos humanos. Para más información, puede visitar el sitio oficial de Espacio Memoria y Derechos Humanos en http://www.espaciomemoria.ar/ 
acerca de los actores sociales y los factores históricos que lo hicieron posible; asimismo, se consideran un legado para las futuras generaciones y un aporte invaluable para la justicia argentina en la actualidad.

Como docentes, consideramos que estos programas son de suma importancia porque invitan a profesores y estudiantes a reflexionar sobre nuestra historia y a tender puentes entre el pasado y el presente, es una invitación a no olvidar y a pensarnos como sujetos transformadores, como ciudadanos activos.

Desde la promulgación de la LEN, también se ha dado impulso a las tecnologías de información y la comunicación, orientado a desarroIlar las competencias necesarias para el manejo de los nuevos lenguajes producidos por las TIC, entre ellos el lenguaje audiovisual. El propósito de esta política educativa se fundamenta con la creación, impulsada desde el Ministerio de Cultura y Educación de la Nación, de portales educativos como Educ.ar ${ }^{7}$ y del canal de televisión Canal Encuentro ${ }^{8}$, donde cuentan con un vasto material audiovisual sobre diversos temas, entre ellos, democracia, derechos humanos e identidad. También, a través del Programa Conectar Igualdad, como política de inclusión digital, que extendió la entrega de computadoras portátiles a alumnos y docentes de escuelas estatales de educación secundaria, educación especial y aulas digitales móviles para los últimos años de los institutos superiores de formación docente estatales de todo el país ${ }^{9}$. Este programa fue impulsado en conjunto desde la Presidencia de la Nación, la Administración Nacional de Seguridad Social (Anses), el Ministerio de Educación de la Nación, la Jefatura de Gabinete de Ministros y el Ministerio de Planificación Federal de Inversión Pública y Servicios. El mismo permite contar con un recurso tecnológico con potencialidades interesantes para propiciar el trabajo de los docentes con el cine en el aula, no solo desde la mirada expectante y la formación del gusto sino también desde la posibilidad de la creación.

7 Educ.ar es un portal educativo, definido como la primera institución de internet del Estado argentino que surge en el año 2003. Su función es principalmente la de orientar a docentes y directivos de instituciones educativas en la incorporación de las tic en las prácticas docentes. Como uno de sus objetivos principales a tener en cuenta están "Facilitar a los docentes herramientas para enseñar en la sociedad del conocimiento y colaborar en la reducción de la brecha digital". Información completa disponible en http://www.educ.ar/.

8 Es el primer canal de televisión del Ministerio de Educación de la República Argentina. Fue creado en mayo de 2005 a través del Decreto N. ${ }^{\circ}$ 533/05. En diciembre de 2006 fue reconocido por la Ley de Educación Nacional N. ${ }^{\circ} 26.206$ y comenzó a transmitir su señal el 5 de marzo de 2007.

9 Programa Conectar Igualdad. Anexo I. Consejo Federal de Educación. Diciembre de 2010. 


\section{El cine en la escuela: una propuesta para el abordaje de la historia reciente}

A lo largo de este artículo hemos mencionado algunos films que nos ayudan a entender ciertos procesos de nuestra historia reciente. Con relación a la última dictadura militar argentina, es posible hallar numerosos films que podemos consultar como docentes, pero antes de hacer mención a algunos de ellos, corresponde aclarar por qué consideramos el cine cómo propuesta didáctica.

El cine ocupa un lugar importante en la historia contemporánea, recreando lo colectivo, recuperando sueños, deseos y esperanzas de gran parte de la humanidad. Felipe y Teruya (2009) invitan a entender el cine como práctica cultural que exige comprender lo que está dicho y sus silencios, aquello que está insinuado, considerando que existe un mensaje pero que no llegará a cada espectador de la misma manera. De este modo, el significado de los mensajes es producto de una interacción entre el cineasta y el espectador, el cual se erige como un sujeto social, que interpreta, se emociona, se identifica y otorga sentido. Igualmente, puede considerarse el cine como "un documento sobre las formas de representación del mundo. El cine de ficción como documento histórico puede responder, fácilmente, a algunas de las cuestiones que se encuentran en continuo movimiento en nuestro presente" (Quintana, 2003, p. 268) y constituye un elemento que nos permite establecer relaciones entre el presente y el pasado, ya que "[...] puede ser un documento útil para comprender las mentalidades de un determinado momento histórico" (p. 268). En este sentido, el trabajo con films en la escuela nos habilita para educar la mirada, precisarla, ajustarla, ampliarla, multiplicarla, inquietarla, ponerla a pensar. Podríamos decir que el cine "nos abre los ojos, los coloca a la distancia justa y los pone en movimiento" (Larrosa, 2006, p. 115). Sin embargo, esta educación de la mirada tiene que ser muy respetuosa, para no opacar la creatividad de quien mira. Y en este sentido, podemos develar uno de los mayores desafíos con los cuales se enfrentan los educadores, el de respetar las reacciones de sus estudiantes frente al cine. Muchas veces, su percepción se expresa con silencio o con gestos y no con palabras y esto es lo que desestabiliza a los adultos: enfrentarse a ese silencio. El silencio no permite develar el sentido, el significado de esa mirada, imposibilita la sensación de seguridad. Es importante que como educadores tengamos en cuenta este desafío en el momento de presentar estrategias didácticas para trabajar con temáticas como la dictadura militar, si consideramos que esta aún constituye una herida abierta para nuestra sociedad.

$\mathrm{Y}$ tal como menciona Larrosa, es preciso considerar que lo importante en las películas es 
justamente lo que no se puede traducir en palabras y, por lo tanto, lo que no se puede formular en términos de ideas [...]. Ni palabras ni ideas. Lo que no quiere decir que el cine no nos haga hablar o no nos haga pensar (Larrosa, 2006, p. 113).

Acerca del trabajo con el cine en la escuela, el cineasta y profesor de cine francés Alain Bergala (2007) menciona que el encuentro con la obra de arte expulsa a los espectadores del sentimiento de confort, de las costumbres consumistas, de lo que está acostumbrado a recibir y consumir. Tenemos que tener en cuenta que el estudiante posee un placer individual en el que la escuela no tiene que intervenir, aunque sí puede cumplir un rol central en iniciar el vínculo con la obra de arte. Pero es preciso tener en cuenta, tal como señala Bergala, que el cine no es algo enseñable; porque el arte no se enseña, se experimenta, se encuentra. En palabras del cineasta, el arte se diferencia del ámbito de "lo enseñable" porque:

se transmite por vías diferentes del discurso del saber único, y a veces, incluso sin ningún tipo de discurso. El quehacer de la enseñanza es la regla, el arte debe ganarse un lugar de excepción dentro de ella [...] el arte debe seguir siendo una experiencia <aparte> dentro de la escuela, a través de la cual los alumnos entren en contacto con su alteridad radical (Bergala, 2007, pp. 34-35).

Si bien el arte no puede ser enseñado, al autor manifiesta que lo que sí puede hacer la escuela es brindar las condiciones para que ese encuentro se produzca, considerando que la escuela es uno de los pocos lugares donde puede producirse ese encuentro.

Retomando el reservorio fílmico sobre los procesos dictatoriales en Argentina ${ }^{10}$, además de los mencionados a lo largo del artículo, es posible mencionar otros como sugerencia para trabajar desde diferentes áreas de conocimiento. En sintonía con los programas señalados, que apelan al trabajo con narrativas o testimonios, podemos pensar en películas documentales como Malvinas, historia de tradiciones (1984), que se refiere a los motivos políticos, económicos y sociales que llevaron a la guerra. Se incluyen testimonios de las Madres de Plaza de Mayo y excombatientes y obreros de Argentina y Gran Bretaña. O en relación a la misma temática, Hundan al Belgrano (1996) que relata los detalles de la Guerra de Malvinas a partir de entrevistas, mapas y escenas dramáticas. También podemos apelar al Documental prohibido (1996) donde se puede analizar la censura mediante testimonios y documentos de la época: cánticos agradecidos, eslóganes publicitarios y exhibiciones televisivas. Otra película

10 Para consultar el repositorio fílmico recomendado por el Ministerio de Educación de la Nación Argentina, consultar: http://www.me.gov.ar/efeme/24demarzo/peliculas.html. 
interesante para trabajar en el nivel secundario es el documental Botín de guerra (1999), que relata la lucha de las Abuelas de Plaza de Mayo por identificar a los niños secuestrados por las Fuerzas Armadas durante la última dictadura, a partir de la recuperación de entrevistas filmadas en Argentina, Suiza y España. Este film permite recuperar la incansable lucha por los derechos humanos y por la recuperación de la identidad de aquellos niños nacidos en cautiverio y expropiados por los dictadores. Cabe destacar que esta temática mantiene gran relevancia en la actualidad de nuestro país, puesto que aún se siguen recuperando niños nacidos en diversos centros clandestinos de detención.

Resulta también interesante recuperar una película más reciente, se trata de Infancia clandestina (2011) del director Benjamín Ávila, hijo de madre desaparecida y actual militante de la agrupación Hijos e Hijas por la Identidad y la Justicia contra el Olvido y el Silencio (Hijos) ${ }^{11}$. Este cineasta rescata experiencias, vivencias y sentimientos de su infancia y crea la historia de Juan (el personaje de la película), un niño hijo de militantes, a partir de su autobiografía. En un artículo reciente en el que se analiza esta película se hace mención de aquello que se pone en juego en el cine con elementos autobiográficos, ya que permite la transformación de lo privado e íntimo en asunto público; en exhibición, se hace de la subjetividad una vía de indagación. De manera que lo que se construye es una versión de la realidad, asumiendo de esta manera que no es posible referirnos en este punto a una "verdad absoluta", sino más bien a "la composición de una historia que revela el punto de vista de cada cineasta" (Gregorini y Martino Ermantraut, 2013, p. 487).

El trabajo con películas que contienen elementos autobiográficos resulta interesante porque permite "ayudar a comprender cómo las personas resignifican los hechos históricos desde el presente, haciendo hincapié en la reconstrucción de aquellos acontecimientos que han marcado la historia personal y configuran la memoria colectiva" (Gregorini y Martino Ermantraut, 2015, p. 306).

Creemos que trabajar desde el cine permite establecer un puente entre el pasado y el presente, no solo desde el avistamiento de los diferentes films sino también a partir de la posibilidad de realización o del pasaje al acto, como lo llama Bergala (2007). Los dispositivos tecnológicos con los que contamos en las escuelas nos brindan la posibilidad del ensayo, y en ese sentido, lo importante es experimentar, vivir la experiencia, porque "el principal objetivo de la realización no es la película realizada como objeto-película, como 'producto', sino la experiencia insustituible de un acto, aunque sea muy modesto, de creación” (Bergala, 2007). El mismo

11 Organización que agrupa a los hijos de los desaparecidos de la última dictadura militar argentina. 
autor sostiene que es indispensable que los alumnos realicen el pasaje al acto de filmación, solo por el hecho de la importancia de vivir esa experiencia, ya que algo sucede a nivel corporal y cerebral que no puede adquirirse con el análisis de películas.

Para concluir este apartado, podemos mencionar que la escuela debe tener en cuenta ciertosaspectos para propiciar la transmisión del cine. Se coincide con Bergala (2007) en que la escuela debe:

» Posibilitar el encuentro de los estudiantes con las películas que serían difíciles de encontrar fuera de la escuela.

» Permitir que el docente se constituya como "pasador", "iniciador", es decir, que se corra de su lugar de docente tal como viene definido y delimitado por la institución y que retome la palabra y el contacto con los alumnos poniendo en juego sus gustos personales y su relación más íntima con tal o cual obra de arte.

» Facilitar un acceso sencillo, permanente, vivo e individualizado a las películas e iniciar a los niños a una lectura creativa y no únicamente analítica y crítica.

» Resistir a la amnesia a la que nos acostumbran los nuevos modos de consumo de las películas y tejer algunos hilos conductores entre las obras del presente y las del pasado.

»Es necesario mencionar que esto no se logra cambiando el pizarrón por una pantalla. De nada nos serviría pensar el cine en la escuela si las prácticas cotidianas responden a otros esquemas, señala Paladino (2006). Lo que se necesita es "reinstalar el cine en el imaginario escolar y pensarlo como algo más que un simple recurso didáctico" (p. 65).

\section{Conclusión}

La política moderna, al tiempo que utiliza la educación como instrumento, encuentra en ella un espacio de resistencia. La posibilidad reveladora de esta tarea, necesariamente intergeneracional, se evidencia en el ejercicio de la reflexión y el pensamiento crítico. En este sentido cabría la posibilidad de preguntarse por qué estamos donde estamos y hacemos lo que hacemos. O en términos arendtianos, ¿cómo problematizar el presente poniendo en tensión el pasado y el futuro? Nuestra propuesta de intervención con relación a la memoria en contextos educativos gira en este sentido, es decir, socavar las bases de la realidad cotidiana hallando explicaciones en el pasado, con vistas a la construcción de un futuro.

A lo largo del artículo intentamos Ilevar a cabo un breve recorrido histórico por la última dictadura militar argentina, asumiendo el compromiso 
intergeneracional que nos convoca como educadores. En el caso de esta propuesta en particular, elegimos el cine como estrategia de intervención adaptada al campo de la educación; esta decisión se basa en las potencialidades que ofrece este tipo de arte contemporáneo, ya que se destacan la imagen, el diálogo y la reflexión como potencialidades asociadas. Además, consideramos que nos encontramos en un momento propicio en nuestro país, ya que contamos con una vasta producción audiovisual para trabajar sobre diferentes temáticas que interesan en nuestro presente y que permiten establecer un puente con el pasado reciente, impulsado desde el Ministerio de Educación Nacional y desde diferentes espacios de la memoria. Por tal motivo decidimos incluir, además del análisis histórico-político, la descripción de algunos films considerados paradigmáticos en la transmisión de contenidos asociados a la memoria y a la reconstrucción del pasado reciente en Argentina, poniendo a disposición de nuestros colegas educadores, el reservorio fílmico que consideramos pertinente para abordar esta temática. 


\section{Referencias bibliográficas}

Arendt, H. (1996). Entre el pasado y el futuro. Madrid: Alianza.

Arendt, H. (1998). Los orígenes del totalitarismo. Madrid: Alianza.

Bergala, A. (2007) La hipótesis del cine en la escuela. Barcelona: Laertes.

Carnovale, V. y Larramendy, A. (2010). Enseñar la historia reciente en la escuela: problemas y aportes para su abordaje. En I. Siede. Ciencias sociales en la escuela. Criterios y propuestas para la enseñanza (pp. 237-265). Buenos Aires: Aique.

Comisión Nacional sobre la Desaparición de Personas, Conadep (1985). Nunca Más. Buenos Aires: Editorial Universitaria de Buenos Aires.

Congreso de la Nación Argentina (1980). Documentos Básicos y Bases Políticas de las Fuerzas Armadas para el Proceso de Reorganización Nacional. Imprenta del Congreso de la Nación: Buenos Aires.

Di Nella, Y. (2007). Psicología de la dictadura. Koyatun: Buenos Aires.

Felipe, D. y Teruya, T. (2009). Narrativas filmicas na educação escolar: construindo processos de alteridade. In Seminário de pesquisa PPE. Maringá, PR: Programa de pós-graduação em educação, Universidade Estadual de Maringá (UEM), Disponible en www.ppe.uem.br/ publicacoes/seminario_ppe_2009_2010/pdf/2009/18.pdf.

Gregorini, V. y Martino Ermantraut, S. Autobiografía y ficción en el cine. (2013). Letras de Hoje. Estudos e debates em linguística, literatura e língua portuguesa, 48, 4.

Gregorini, V. y Martino Ermantraut, S. (2015). Narrativa autobiográfica en el cine: una alternativa para la enseñanza de la historia reciente. Revista História Hoje, 4 (7), 295-312 - Revista Electrónica De História e Ensino. Anpuh-Brasil. Recuperado de: http://rhhj.anpuh.org/ojs/ index.php/RHHJ

Larrosa, J. (2006). Niños atravesando el paisaje. Notas sobre cine e infancia. En I. Dussel, y D. Gutiérrez (comps.). Educar la mirada: políticas y pedagogías de la imagen. Buenos Aires: Manantial.

Ley de Educación Nacional N.`26206 (2006). Recuperado de: http:// www.me.gov.ar/doc_pdf/ley_de_educ_nac.pdf

Lorenz, F. (2006). El pasado reciente en la Argentina: las difíciles relaciones entre transmisión, educación y memoria. En Enseñanza de la historia y memoria colectiva (pp. 267-285). Buenos Aires: Paidós.

Ministerio de Cultura y Educación. (1977). Subversión en el ámbito educativo (conozcamos a nuestro enemigo). Buenos Aires: autor.

Paladino, D. (2006). Qué hacemos con el cine en el aula. En I. Dussel y D. Gutiérrez (comps.). Educar la mirada: políticas y pedagogías de la imagen. Buenos Aires: Manantial. 
Quintana, A. (2003). Fábulas de lo visible: el cine como creador de realidades. Barcelona: Acantilado.

Seoane, M. y Núñez, H. (1986). La noche de los lápices. Buenos Aires: Contrapunto.

Zizek, S. (2008). Sobre la violencia. Seis reflexiones marginales. Argentina: Paidós.

\section{Filmografía}

Asociación Abuelas de Plaza de Mayo. (Productora). (2007). Televisión por la identidad. [Serie televisiva]

Ávila, B. (Director). (2012). Infancia clandestina. Argentina, Brasil y España.

Blaustein, D. (Director). (2000). Botín de Guerra. Argentina.

Denti, J. (Director). (1984). Malvinas, historia de tradiciones. Argentina y México.

Di Tella, A. (Director). (1996). Prohibido. Argentina.

Kölsch, J. (Director). (2006). Hannah Arendt. Pensar apasionadamente. [Documental] Disponible en https://www.youtube.com/watch?v=zaHHP2h-nDs.

Olivera, H. (Director). (1986). La noche de los lápices. Argentina.

Pontecorvo, G. (1966). La batalla de Argel. Italia, Argelia.

Puenzo, L. (Director). (1985). La historia oficial. Argentina.

Robin, M. M. (Directora). (2003). Escuadrones de la muerte. La escuela francesa. Argentina, Francia.

Trotta, M. von. (Directora). (2012). Hannah Arendt (la película). Alemania, Luxemburgo y Francia.

Urioste, F. (Director). (1996). Hundan al Belgrano. País: Argentina. 